\title{
Preprocessing cotton to prevent byssinosis
}

\author{
JAMES A. MERCHANT', JOHN C. LUMSDEN ${ }^{2}$, KAYE H. KILBURN, \\ VICTOR H. GERMINO ${ }^{1}$, JOHN D. HAMILTON ${ }^{1}$, WILLIAM S. LYNN ${ }^{1}$, \\ H. BYRD ${ }^{2}$, and D. BAUCOM ${ }^{2}$ \\ Duke University Medical Center, Durham, North Carolina ${ }^{1}$ and Occupational Health Section, \\ Division of Epidemiology, North Carolina State Board of Health, Raleigh, North Carolina, U.S.A.
}

Merchant, J. A., Lumsden, J. C., Kilburn, K. H., Germino, V. H., Hamilton, J. D., Lynn, W. S., Byrd, H., and Baucom, D. (1973). British Journal of Industrial Medicine, 30, 237-247. Preprocessing cotton to prevent byssinosis. A fundamental approach of cleaning or deactivating cotton prior to manufacturing has long been advocated to prevent byssinosis, but no trial had been conducted to test the feasibility of such an approach. In the study described, it was possible to be directed by both biological observations and the results of manufacturing trials.

An exposure chamber was built in a cotton textile mill which had been previously studied as part of a large cross-sectional survey. The chamber was provided with an independent air conditioning system and a carding machine which served as a dust generator. Sixteen subjects, who had shown reductions in expiratory flow rate with exposure to cotton dust, were chosen to form a panel for exposure to raw cottons and cottons which had been preprocessed by heating, washing, and steaming. Indicators of effects were symptoms of chest tightness and/or dyspnoea, change in $\mathrm{FEV}_{1 \cdot 0}$, and fine dust levels over 6 hours of exposure.

Exposure of the panel to no cotton dust resulted in no change in $\mathrm{FEV}_{1.0}$ and served as the control for subsequent trials. Exposure to strict middling cotton resulted in a byssinosis symptom prevalence of $22 \%$, a significant decrement in $\mathrm{FEV}_{1.0}$ of $2.9 \%$, and a fine dust level of $0.26 \mathrm{mg} / \mathrm{m}^{3}$. Exposure to strict low middling cotton resulted in a byssinosis symptom prevalence of $79 \%$, a decrement in $\mathrm{FEV}_{1.0}$ of $8.5 \%$, and a fine dust level of $0.89 \mathrm{mg} / \mathrm{m}^{3}$. Oven heating strict low middling cotton resulted in a byssinosis symptom prevalence of $56 \%$ and a relatively greater drop in $\mathrm{FEV}_{1.0}$ of $8.3 \%$ for $0.48 \mathrm{mg} / \mathrm{m}^{3}$ of fine dust. Washing the strict low grade cotton eliminated detectable biological effects with a symptom prevalence of $8 \%$, an increase of $1.4 \%$ in $F E V_{1.0}$, and a dust level of $0.16 \mathrm{mg} / \mathrm{m}^{3}$, but the cotton proved to be difficult to process. As an alternative method, strict low middling cotton was steamed initially in large dyeing vats, on a conveyor, in an autoclave, and in a modified yarn dyeing apparatus or 'pipe' steamer. Of these methods, autoclaving cotton was the most successful, reducing symptom prevalence to $8 \%$, the drop in $\mathrm{FEV}_{1.0}$ to $0.4 \%$, and the dust level to $0.23 \mathrm{mg} / \mathrm{m}^{3}$. Development of a high capacity cotton steamer based on the small 'pipe' steaming model resulted in a symptom prevalence of $8 \%$, a decrement in $\mathrm{FEV}_{1.0}$ of $0.8 \%$, and a mean dust level of $0.27 \mathrm{mg} / \mathrm{m}^{3}$. Regressions calculated from raw and high capacity steaming trials indicate that at low dust levels steamed cotton dust was roughly one half as biologically active as raw cotton dust.

Source intervention, which has been successfully and often dramatically applied to epidemic infectious diseases, has long been advocated to prevent byssinosis (Schilling et al., 1964). Although investi- gators early in the century recommended dust suppression to eliminate respiratory disease (Collis, 1915-16), subsequent efforts to reduce dust levels have failed to reduce significantly the harmful 
exposure to workers (Schilling, 1956; Molyneux and Tombleson, 1970), largely because current machine exhaust and mill ventilation systems fail to reduce significantly the concentrations of fine dust (McKerrow, Roach, Gilson, and Schilling, 1961; Wood and Roach, 1964). Because levels of lint free dust $(\leqslant 15 \mu \mathrm{m})$ of 0.1 to $0.2 \mathrm{mg} / \mathrm{m}^{3}$ are associated with a byssinosis prevalence of 6 to $13 \%$, it is clear that efficient dust control is necessary (Merchant et al., 1972). Schilling noted 'the wide prevalence of byssinosis in the cotton industry and the obvious inadequacy and high cost of prevention by locally applied exhaust ventilation' and called for consideration of 'a more fundamental approach to dust control-namely, the removal of plant debris from cotton where it is ginned. Such measures might include a mechanical method of removing the dust or washing the cotton to take out the water soluble agent causing byssinosis' (Schilling et al., 1964).

Materials in aqueous extracts of cotton trash cause chest tightness and bronchoconstriction in human subjects, which suggests that this fraction contains the causal agent(s) of byssinosis (Bouhuys, Lindell, and Lundin, 1960; Hamilton et al., 1973). El-Batawi and El-Din Shash (1962) observed that workers who processed scoured cotton for medical use had no symptoms of byssinosis and no decrease in expiratory flow rates. Further, it has been observed that those who 'wet finish' flax consistently have a lower prevalence of byssinosis than 'other finishers' (Carey et al., 1965). McDermott, Skidmore, and Edwards (1968) reported that dust from washed cotton increased airway resistance and decreased the forced expiratory volume in one second $\left(F E_{1 \cdot 0}\right)$ less than unwashed cotton dust, and in vivo had only $50 \%$ of the histamine activity of the unwashed dust. Although washing cotton prior to processing has been proposed and supported by the above observations, there has been no field trial of this technique to prevent byssinosis. Initially, a limited study of washed and unwashed cotton was planned using a selected panel of cotton textile workers, dust levels, and spinning quality of cotton as indicators of effects. Later the study was extended to trials of steamed cottons using $225 \mathrm{~kg}$ experimental lots, and finally to trials with cotton which was part of several $450 \mathrm{~kg}$ lots processed through a production model steamer.

\section{Methods}

\section{Experimental chamber design}

To create an exposure chamber, a corner of the mill which was separate from manufacturing and measured $15 \mathrm{ft}(4.6 \mathrm{~m})$ in width $\times 60 \mathrm{ft}(18.3 \mathrm{~m})$ in length and $20 \mathrm{ft}(6.1 \mathrm{~m})$ in height was enclosed and tightly sealed. The plant air conditioning duct to that area was closed and an air conditioning unit with $88625 \mathrm{~kJ}$ capacity was installed to provide fresh air drawn from outside the mill and uniform temperature and humidity and to maintain a positive pressure relative to the remainder of the mill. The air conditioner was equipped with pleated media filters which were changed before each trial. A hopper-feeder and high speed $(18 \mathrm{~kg} / \mathrm{hr})$ carding machine, which was exhaust ventilated to an attached bag, was installed to process raw materials (Appendix 1) to a sliver and to serve as the dust generator. The chamber was vigorously vacuumed and the air exchanged for several hours between experimental trials.

\section{Selection of subjects}

A panel of 16 workers, eight from the first and eight from the second shift, was selected based on their decrement in FEV 1.0 with cotton dust exposure (Table 1). No one with a history of chronic bronchitis or $\mathrm{FEV}_{\mathbf{1} \cdot 0}$ less than $77 \%$ of predicted was accepted. All had shown decrements of greater than $200 \mathrm{ml}$ or $5 \%$ of their preexposure FEV $_{1.0} 6$ hours after exposure. Other selection factors were dependability and informed consent to participate in a prolonged experiment. Grade of byssinosis, smoking history, work area, and duration of cotton dust exposure did not affect selection.

All 16 subjects were men; five were black and 11 were white. Their mean age was 35 years and the mean duration of cotton dust exposure was eight years. Of the 12 with a history of cigarette smoking, the mean number of pack years was $18 \cdot 2$ (Table 1). Ten had been diagnosed as having grade $1 / 2$ or grade 2 byssinosis, none was bronchitic or dyspnoeic by questionnaire, ${ }^{1}$ but two had a history of asthma. Their mean FEV $_{1 \cdot 0}$ during the plant wide survey was over $3700 \mathrm{ml}$, a mean $96.1 \%$ of predicted for height and age (Boren, Kory, and Syner, 1966). Their mean decrement in $\mathrm{FEV}_{1.0}$ during the survey was $374 \mathrm{ml}$ or $10.1 \%$ of their baseline value. None showed evidence of emphysema by chest radiography (Sutinen, Christoforidis, Klugh, and Pratt, 1965).

Following the initial trials, when it became apparent that many more months would be involved in the project, the panel was reduced from 16 to 12 . One of the four had moved to another town, one had been having unrelated medical problems, and two others had shown no consistent response to cotton dust. The same panel of 12 subjects, six from the first shift and six from the second shift, with one exception (trial 24) participated in every trial.

\section{Observations during experimental trials}

The panel was always tested on Monday, usually following at least two days (64 hours) away from mill exposure. Five trials were conducted after one day ( 40 hours) away from mill exposure. Before exposure began, a series of baseline forced vital capacities was obtained. Both assessment of symptoms and $\mathrm{FEV}_{\mathbf{1 . 0}}$ at 2-hour intervals after the beginning of exposure $(10 \mathrm{am}, 12$ noon, and $2 \mathrm{pm}$ for first shift, and $6 \mathrm{pm}, 8 \mathrm{pm}$, and $10 \mathrm{pm}$ for second shift) were used as indicators of response to cotton dust. Panel members were asked not to smoke in the hour before exposure nor during exposure. If subjects had to

${ }^{1}$ For questionnaire, obtain document from ASIS, National Auxiliary Publications Service, c/o CCM Information Corp. 866 Third Avenue, New York, N.Y., 10022. 
TABLE 1

Preprocessing Cotton to Prevent Byssinosis: Panel Profile

\begin{tabular}{|c|c|c|c|c|c|c|c|c|c|c|c|}
\hline \multirow{3}{*}{$\begin{array}{r}\text { Subject } \\
1^{1}\end{array}$} & \multirow{2}{*}{$\begin{array}{l}\text { Age } \\
(y r)\end{array}$} & \multirow{2}{*}{$\begin{array}{c}\text { Race } \\
\mathrm{N}\end{array}$} & \multicolumn{2}{|c|}{$\begin{array}{l}\text { Cotton exposure } \\
\text { (work area) }(y r)\end{array}$} & \multirow{2}{*}{$\begin{array}{c}\begin{array}{c}\text { Smoking } \\
\text { history } \\
\text { (cigarette } \\
\text { pack yr) }\end{array} \\
5\end{array}$} & \multirow{2}{*}{$\begin{array}{c}\text { Byssinosis } \\
\text { grade }\end{array}$} & \multirow{2}{*}{$\begin{array}{c}\text { Asthma } \\
\text { history } \\
0\end{array}$} & \multirow{2}{*}{$\begin{array}{c}\begin{array}{c}\text { Survey } F E V_{1 \cdot 0} \\
\text { before work } \\
(m l)\end{array} \\
3750\end{array}$} & \multirow{2}{*}{$\begin{array}{c}\begin{array}{c}\% \text { of } \\
\text { pred. } \\
\text { FEV }\end{array} V_{1 \cdot 0} \\
84\end{array}$} & \multicolumn{2}{|c|}{$\begin{array}{l}F E V_{1 \cdot 0} \\
6 h r \text { exposure } \\
(m l) \quad(\%)\end{array}$} \\
\hline & & & Roving & 4 & & & & & & -250 & $-6 \cdot 7$ \\
\hline & 24 & $\mathbf{N}$ & Drawing & 3 & 4 & 2 & 0 & 3660 & 83 & -360 & -9.8 \\
\hline 3 & 52 & C & Carding & 35 & 0 & 2 & 0 & 2610 & 77 & -280 & -10.7 \\
\hline 4 & 34 & $\mathrm{C}$ & Spinning & 15 & $10^{2}$ & 0 & 0 & 3790 & 99 & -410 & -10.8 \\
\hline $5^{1}$ & 26 & $\mathbf{N}$ & Roving & 4 & 0 & $1 / 2$ & 0 & 3880 & 79 & -380 & -9.8 \\
\hline 6 & 26 & $\mathbf{N}$ & Spinning & 4 & 0 & 0 & + & 3950 & 94 & -830 & -21.0 \\
\hline 7 & 32 & C & Opening & 2 & 15 & 0 & 0 & 4450 & 101 & -350 & -7.8 \\
\hline 8 & 48 & $\mathrm{C}$ & Spinning & 1 & 32 & $1 / 2$ & 0 & 3680 & 108 & -330 & -9.0 \\
\hline 9 & 37 & C & Carding & 7 & 30 & 2 & 0 & 3350 & 89 & -360 & -10.5 \\
\hline 10 & 42 & $\mathrm{C}$ & Spinning & 22 & 25 & 0 & 0 & 3900 & 113 & -400 & $-10 \cdot 3$ \\
\hline 11 & 26 & C & Roving & 4 & $20^{2}$ & 0 & 0 & 3350 & 79 & -300 & $-9 \cdot 0$ \\
\hline 12 & 25 & C & Spinning & 3 & $15^{2}$ & $1 / 2$ & + & 5080 & 134 & -320 & $-6 \cdot 3$ \\
\hline 13 & 21 & $\mathbf{N}$ & Spinning & 1 & 0 & $1 / 2$ & 0 & 3350 & 89 & -490 & $-14 \cdot 6$ \\
\hline 14 & 39 & C & Winding & 18 & 23 & $1 / 2$ & 0 & 3600 & 96 & -350 & -9.7 \\
\hline $15^{1}$ & 45 & C & Picking & 1 & $50^{2}$ & $1 / 2$ & 0 & 4000 & 117 & -350 & -8.8 \\
\hline $16^{1}$ & 48 & C & Winding & 3 & $62^{2}$ & 0 & 0 & 3000 & 97 & -220 & $-7 \cdot 3$ \\
\hline Totals & $35 \cdot 1$ & & & 7.9 & $18 \cdot 2$ & & & 3713 & $96 \cdot 1$ & -374 & $-10 \cdot 1$ \\
\hline
\end{tabular}

${ }^{1}$ Those dropped from panel ${ }^{2}$ Ex-smoker $\mathrm{N}=$ Negro; $\mathrm{C}=$ Caucasian

leave the chamber for a few minutes, a mask capable of filtering respirable particles was provided. The only work required was to keep the hopper fed with cotton and the carding machine operating at high speed. After 2 hours of exposure each subject was asked whether he "noticed any difference' in his breathing since coming into the chamber. Those who did were asked to describe their symptoms which were recorded. A waterless spirometer ${ }^{1}$ was used to record four forced expirations from which FEV $_{1.0}$ was calculated. Further expirations were requested if the two highest records, the mean of which was the accepted $\mathrm{FEV}_{1 \cdot 0}$, were not within $200 \mathrm{ml}$ of each other. All FEV $_{1.0}$ were recorded by V.G. and J.M. and all FEV $_{1 \cdot 0}$ measured by J.M. Symptom prevalence and mean change in $\mathrm{FEV}_{1.0}$ were recorded at intervals of 2 hours during exposure (Appendix 2).

\section{Dust sampling}

Dust samples were collected during both shifts with three dust samplers. A General Metal Works high volume device, sampling approximately $1.7 \mathrm{~m}^{3}$ per minute, collected total lint and dust on a fibreglass mat. A cyclone dust sampler (Lynch, 1970) separated the dust into a lint fraction, a middle fraction of approximately $11 \mu \mathrm{m}$ to $2 \mathrm{~mm}$, and a fine fraction of approximately $10 \mu \mathrm{m}$ and below. A vertical elutriator (Lynch, 1970) sampling particles with a mass median aerodynamic diameter of $15 \mu \mathrm{m}$ and below was also used but the sample weights are not reported because this sampler was modified during the study. During early trials, two 3-hour samples were collected during the first shift but later 6-hour samples were collected for each shift. The

1Jones Pulmonor II, Jones Medical Instrument Corp., Oakbrook, Illinois, U.S.A. mean value of the two or three samples (Appendix 2) of the fine fraction from the cyclone separator is defined as 'respirable dust' to correlate with biological responses.

\section{Raw materials and trial sequence}

A total of 33 experimental trials were conducted beginning in the summer of 1970 and ending in the spring of 1972. The cotton used for positive control trials and all washing, heating, and steaming trials came from the same supply and from two lots of cotton set aside for these experiments. Five hundred pounds of raw material were consumed in each trial.

Initially, trials with raw cotton were done to establish the sensitivity of the panel, and trials with no cotton dust exposure to serve as negative controls to account for diurnal variation in flow rates. The effect of improving the grade of cotton, the effect of low gossypol cotton, and the effect of mechanically cleaning cotton by running it through the picking process were all evaluated in individual trials. To test the effect of heat on cotton dust, two trials were completed with oven-heated cotton. Three trials with washed cottons were completed but were not pursued further because of difficulty in processing cotton so washed. Steaming cotton in large dyeing vats was then tried as an alternative to washing. In an effort to steam cotton in a way that could easily be integrated into the manufacturing process, cotton was steamed on a conveyor, in an autoclave, and in a small 'pipe' steamer adapted from dyeing wool yarn. After five trials with the small pipe steamer a large production model steamer using the same principle was built and the remaining trials were conducted on cotton preprocessed through this device. In an effort to increase the effectiveness of steaming, the duration of steaming was extended to 7 minutes for three trials but was then reduced 
to 5 minutes when some difficulty was encountered in processing without an accompanying reduction in biological activity.

\section{Statistical analysis}

Both negative control trials 1 and 2 were tested against each exposure for differences in $F E_{1.0}$ from before exposure to after 6 hours of exposure by use of paired $t$ tests. Linear regressions and correlation coefficients were calculated for all raw cotton trials and all production steamed cotton trials. Differences in theslope of raw cotton and steamed cotton regressions were tested (Dixon and Massey, 1969). A P value of $\leq 0.05$ was accepted as the level of significance and levels of $P \leq 0 \cdot 1$ were recorded (Appendix 2).

\section{Results}

\section{Untreated and heated cotton}

Two control runs (trials 1 and 2) conducted in the exposure chamber without cotton dust exposure did not affect FEV $_{1.0}$ (Table 2, Fig. 1). Two of 16 subjects reported symptoms consistent with byssinosis (chest tightness and/or shortness of breath) with rayon exposure. Respirable dust levels were low with both runs. Both strict middling grades of cotton (trials 3 and 4 ) produced moderate drops in FEV $_{1 \cdot 0}$ but only low gossypol cotton (trial 3) was significant by paired $t$ tests. Strict middling cotton resulted in respirable dust levels averaging 0.26 $\mathrm{mg} / \mathrm{m}^{3}$ and $22 \%$ of the subjects reported byssinosis symptoms. The $50 \%$ strict middling cotton $/ 50 \%$ polyester blend resulted in a drop in $\mathrm{FEV}_{\mathbf{1 . 0}}$ of slightly more than $1 \%$, no byssinosis symptoms, and a respirable dust level somewhat lower than for unblended strict middling cottons (Table 2, Fig. 1).

Raw low grade cottons (trials 6,7, and 8) resulted

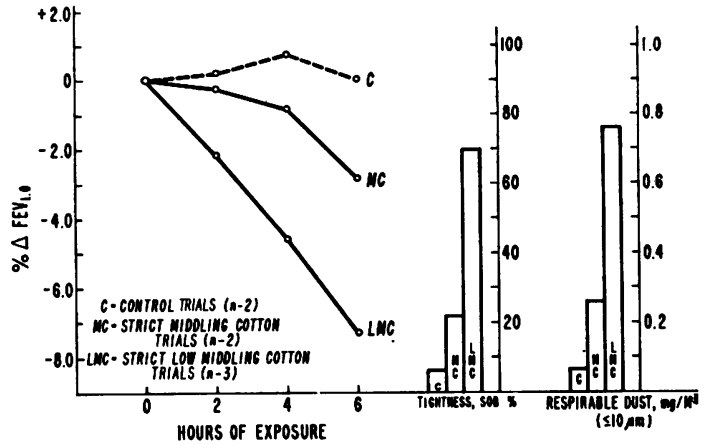

FIG. 1. Grouped percent change in $\mathrm{FEV}_{1.0}$, percentage with chest tightness and/or dyspnoea, and respirable dust levels over 6 hours of exposure to control trials and trials of strict low middling and middling cottons, North Carolina, 1970-72.

in highly significant decrements in $\mathrm{FEV}_{\mathbf{1 . 0}}$, more than $50 \%$ of the subjects with byssinosis symptoms, and high respirable dust levels ranging from 0.51 to $1.15 \mathrm{mg} / \mathrm{m}^{3}$. In trial 6 the heaviest respirable dust level was recorded and 15 of 16 subjects reported chest tightness and/or shortness of breath (Table 2, Fig. 1). Oven-heated cotton produced highly significant drops in $\mathrm{FEV}_{\mathbf{1 . 0}}$, symptoms in more than half of the subjects, and relatively greater decrements in $\mathrm{FEV}_{\mathbf{1 . 0}}$ per milligramme of dust than did untreated low grade cotton (Table 2, Fig. 2).

Washed and steamed cotton

The three trials with washed cotton resulted in a

TABLE 2

Summary of Exposure Trials

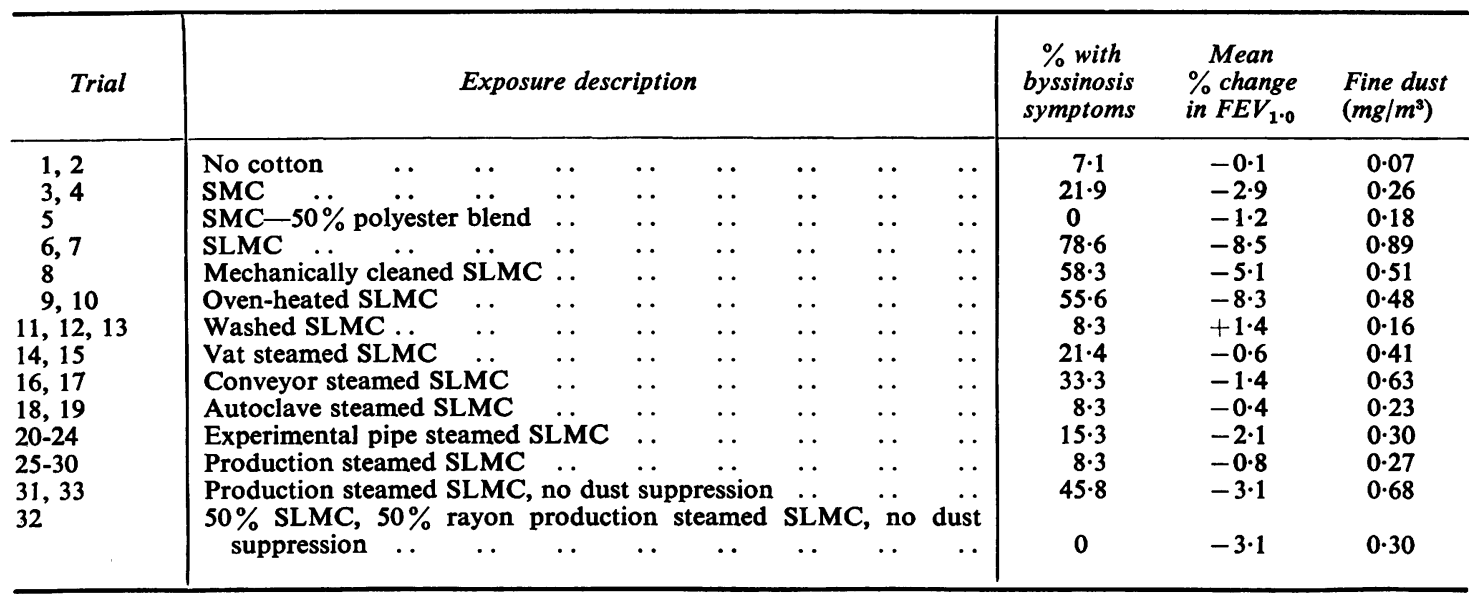

SMC = strict middling cotton $;$ SLMC $=$ strict low middling cotton 


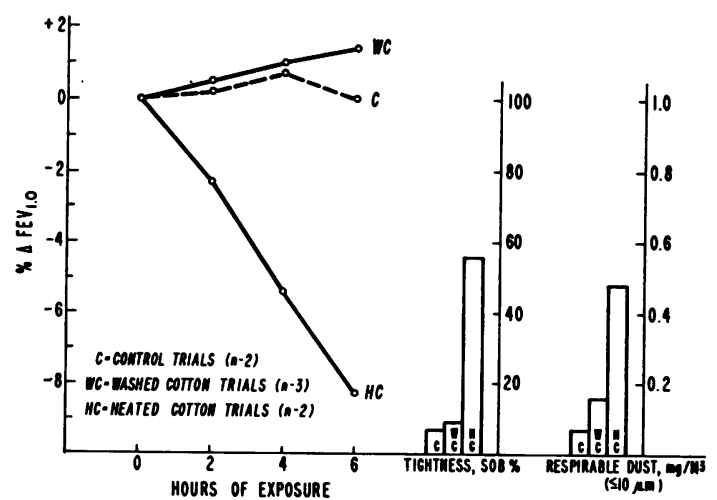

FIG. 2. Grouped percent change in $\mathrm{FEV}_{1.0}$, percentage with chest tightness and/or dyspnoea, and respirable dust levels over 6 hours of exposure to control trials and trials of washed and heated cottons, North Carolina, 1970-72.

slight increase in $\mathrm{FEV}_{\mathbf{1 . 0}}$ over 6 hours of exposure, and byssinosis symptoms in less than $10 \%$ of the subjects. Respirable dust levels were roughly a quarter that obtained with raw cotton, the lowest level $\left(0.07 \mathrm{mg} / \mathrm{m}^{3}\right)$ obtained with the commercially washed medical cotton (trial 12) (Table 2, Fig. 2).

Steaming cotton in the dyeing vat resulted in small and insignificant group decrements in $\mathrm{FEV}_{\mathbf{1 . 0}}$ and symptoms in $21 \%$ (Table 2, Fig. 3). Dust levels were reduced by roughly one half when compared with raw low grade cottons. Both trials with conveyor wetted and steamed cottons resulted in small and insignificant drops in $\mathrm{FEV}_{1.0}$, but symptoms in one third of the subjects. Although trial 17 resulted in

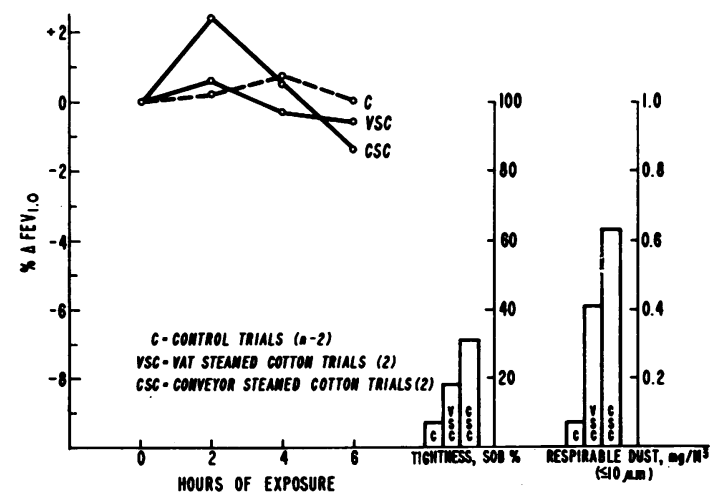

FIG. 3. Grouped percent change in $\mathrm{FEV}_{1.0}$, percentage with chest tightness and/or dyspnoea, and respirable dust levels over 6 hours of exposure to control trials and trials of vat steamed and conveyor steamed cottons, North Carolina, 1970-72. a very heavy dust concentration $\left(0.95 \mathrm{mg} / \mathrm{m}^{3}\right)$, the mean respirable dust level for trials 16 and 17 was still 0.7 of the mean dust level of the positive control trials (Table 2, Fig. 3).

One of the two autoclaved cotton runs resulted in no drop in $\mathrm{FEV}_{1.0}$ and the other in an insignificant drop in FEV $_{1.0}$ of less than $1 \%$. Symptoms were reported by $8 \%$ of the subjects and the respirable dust level was reduced to a quarter that of the raw cotton control trials (Table 2, Fig. 4).

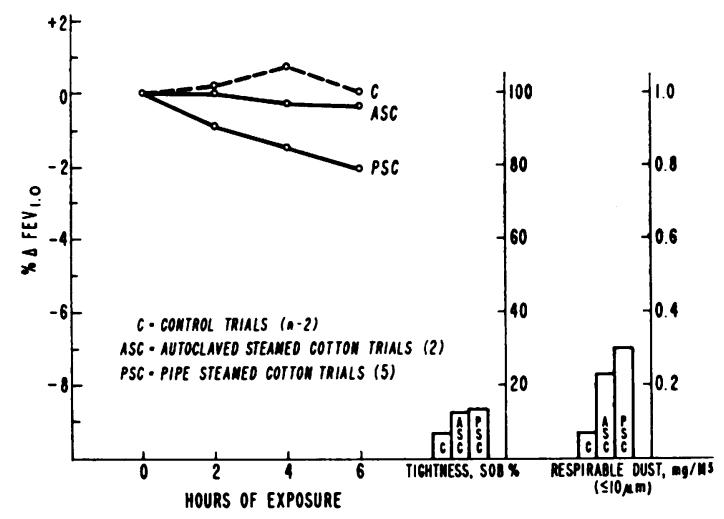

FIG. 4. Grouped percent change in $\mathrm{FEV}_{1.0}$, percentage with chest tightness and/or dyspnoea, and respirable dust levels over 6 hours of exposure to control trials and trials of autoclaved and pipe steamed cottons, North Carolina, 1970-72.

Of the five trials with experimental pipe-steamed cotton, two resulted in a significant decrement in group $\mathrm{FEV}_{1 \cdot 0}$, trial 22 with a decrement of $2.8 \%$, and trial 24 with a drop of $3.0 \%$ (Table 2, Fig. 4). Symptoms for all trials were recorded in over $15 \%$ of the subjects and ranged from $25 \%$ (trials 22 and 23) to no symptoms (trial 21). Respirable dust levels were consistently reduced during all five trials and averaged one third that of the mean raw cotton positive control respirable dust level (Table 2, Fig. 4).

With trials of production steamed cotton (trials 25 to 30), the changes in $\mathrm{FEV}_{1.0}$ compared with control trials were uniformly small and insignificant. Symptoms of chest tightness and/or dyspnoea occurred in $8 \%$ considering all trials together. Dust levels were consistently reduced, averaging 0.27 $\mathrm{mg} / \mathrm{m}^{3}$ over the six trials (Table 2, Fig. 5). Although the dust levels were slightly lower with the cotton steamed for 7 minutes, there was no detectable difference in the biological effects of the 7-minute and the 5-minute steamed cottons. We were advised that the spinning quality of the cotton steamed for 


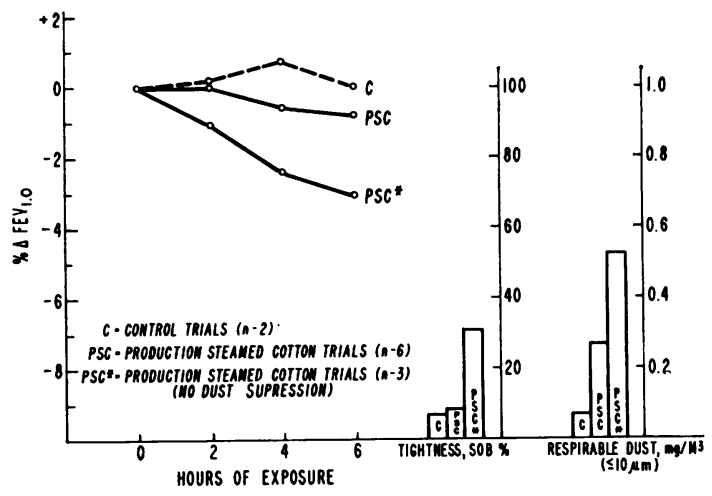

FIG. 5. Grouped percent change in $\mathrm{FEV}_{1.0}$, percentage with chest tightness and/or dyspnoea, and respirable dust levels over 6 hours of exposure to control trials and trials of production steamed cotton with and without dust suppression, North Carolina, 1970-72.

5 minutes was superior to that which was steamed longer.

Three trials with production steamed cotton (trials 31 to 33), without dust suppression, resulted in moderate and significant decrements in FEV $_{1 \cdot 0}$. In trials 31 and 33, a quarter to two thirds of the subjects reported chest tightness and/or dyspnoea. Trial 32, which tested a cotton/rayon blend, also resulted in a significant decrease in $F V_{1 \cdot 0}$, but no symptoms with a lower dust level of $0.30 \mathrm{mg} / \mathrm{m}^{3}$ (Table 2, Fig. 5).

When the regression equation for symptom prevalence by respirable dust level (Fig. 6) for raw cotton trials (trials 3 to 8) was calculated, a strong linear correlation between symptoms and dust level was found $(r=0.93)$. When the same regression was calculated for the 12 subjects for production steamed cottons (trials 25 to 33), the strength of the linear association was not as great $(r=0.74)$. The regression line for steamed cottons was nearly parallel to that of the raw cotton but shifted to the right, suggesting a lower prevalence of symptoms at all respirable dust levels. Thus, at low respirable dust levels of 0.1 and $0.2 \mathrm{mg} / \mathrm{m}^{3}$, two to three times as much steamed cotton dust as raw cotton dust was required to produce the same symptom prevalence. When percent change in $\mathrm{FEV}_{\mathbf{1 . 0}}$ by respirable dust level was considered (Fig. 7), the linear correlation for raw cotton dust was again strong $(r=0.99)$. When the same regression equation was calculated for the production steamed cotton trials, the correlation coefficient was 0.59 . The slope of the steamed cotton regression line was somewhat flatter than that for raw cotton and the difference in slopes was statistically significant $(P \leq 0.025)$. Again the

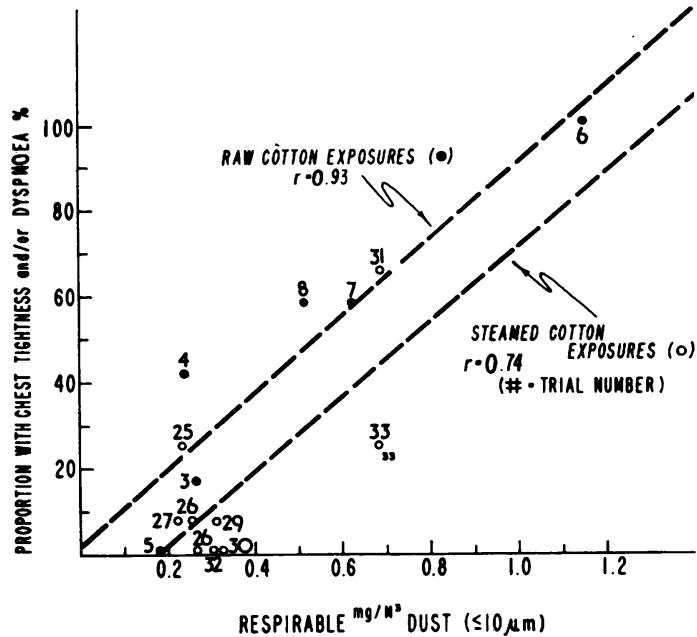

FIG. 6. Proportion with chest tightness and/or dyspnoea by respirable dust level in a panel of cotton textile workers with exposures to raw cotton and steamed cotton, North Carolina, 1970-72.

steamed cotton regression line was shifted to the right of that for raw cotton, suggesting that, at all dust levels, roughly twice as much steamed cotton dust as raw cotton dust was required to produce the

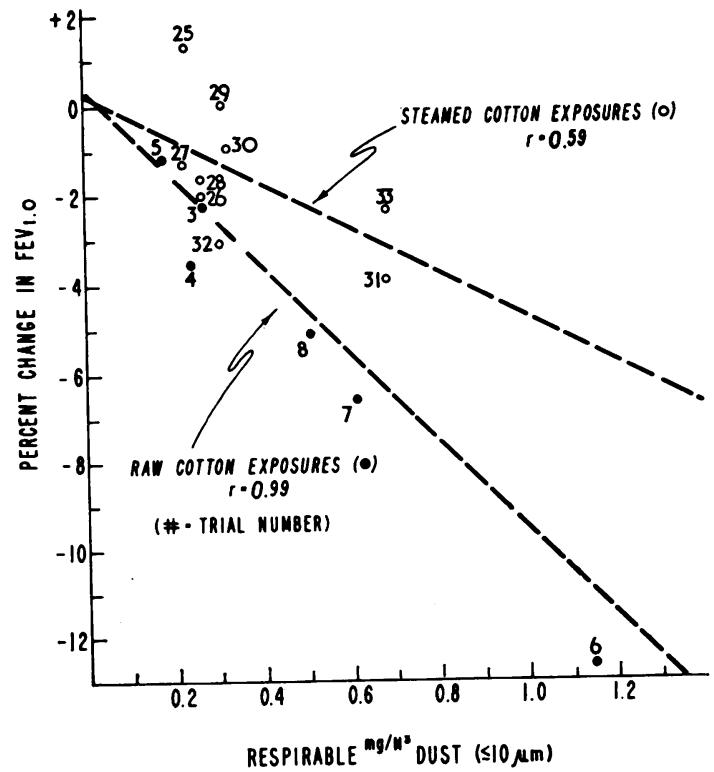

FIG. 7. Percent change in $\mathrm{FEV}_{1.0}$, by respirable dust level in a panel of cotton textile workers with exposures to raw cotton and steamed cotton. North Carolina, 1970-72. 
same decrement in $\mathrm{FEV}_{\mathbf{1 . 0}}$. The correlation between percent change in $\mathrm{FEV}_{\mathbf{1 . 0}}$ and byssinosis symptom prevalence for the six raw cotton trials (including all 16 subjects in trials 3,4 , and 6) was also strong $(r=0.97)$. However, when the same calculation was made for production steamed cotton trials, the correlation coefficient was only $0 \cdot 34$.

\section{Discussion}

Recent cross-sectional studies of the prevalence of byssinosis in the United States textile industry (Bouhuys et al., 1969; Zuskin et al., 1969; Schrag and Gullet, 1970; Merchant et al., 1972, 1973a, 1973b) have affirmed for the United States the conclusion expressed in the summary of the 1962 Byssinosis Conference in Manchester, United Kingdom, that byssinosis is widely prevalent in the cotton textile industry. Clearly, a method that would remove or de-activate cotton dust during picking or ginning would most efficiently solve this problem. To consider such an approach one must be prepared to test both biological effects and manufacturing effects of intervention, since knowledge of both are mandatory if a solution is to be achieved. It was possible in this study to make both sets of observations and to be directed by positive results. Biological observations are discussed below; conclusions as to the spinning efficacy of washed and steamed cotton are best judged by the manufacturer's willingness to put cotton so processed into production. In addition to observations concerning the potential of washing and steaming cotton to prevent byssinosis, dose response relationships were developed and clues were found concerning the agent(s) causing byssinosis.

\section{Dose-response observations}

Several cross-sectional investigations have demonstrated that a strong linear relationship exists between symptoms of byssinosis and cotton dust concentration (Roach and Schilling, 1960; Molyneux and Berry, 1968; Merchant et al., 1973b) and decrement, in FEV $_{\mathbf{1 . 0}}$ and dust concentration (ElBatawi, Schilling, Valić, and Walford, 1964; Berry and Molyneux, 1968; Merchant et al., 1973b). Byssinosis prevalence in excess of $90 \%$ has been recorded in Egypt where workers beat flax in their homes and live in a dense dust cloud (El-Batawi and Hussein, 1964). This suggests that, although there is a spectrum of human sensitivity to the agent(s) in cotton dust, individual resistance can be overcome by exposure to a very high dose. Dose-response curves from crosssectional studies may result in comparison of heterogeneous populations at different dust levels and are complicated by the undefinable element of selective migration. By contrast, this panel study provided a uniform group in which to observe biological effects over a range of respirable dust levels. Over the six trials involving raw cotton (Figs 6 and 7), the linear association between both symptoms and decrement in $\mathrm{FEV}_{1 \cdot 0}$ with respirable dust level is striking. All of the 12 panel subjects reported chest tightness and/or dyspnoea during trial 6 , in which the dust level was $1.15 \mathrm{mg} / \mathrm{m}^{3}$. Five of these men had no previous history of chest tightness with cotton dust exposure. This suggests that the major variable in human responsiveness is dose. Susceptibility may be affected by co-factors such as cigarette smoking (McKerrow and Schilling, 1961; Merchant et al., 1972, 1973a) and underlying airway disease which may increase the retained dose by interfering with bronchial clearance.

\section{Observations concerning aetiological agents}

Much of the beneficial effect realized by washing and steaming was secondary to dust reduction, which was more complete with washing. Of the dust that remained after washing, no biological activity could be detected by our indicators, although the respirable dust level with one trial was as high as $0.26 \mathrm{mg} / \mathrm{m}^{3}$. This is consistent with the concept that the agent(s) causing byssinosis symptoms is water soluble and therefore selectively removed (El-Batawi and El-Din Shash, 1962; McDermott et al., 1968). Similarly, the active material appears to be selectively removed by steam, leaving behind a relatively more inert dust. Of special interest were the two trials with autoclaved cotton in which the bale was unopened, thus wrapped and tightly bound; nevertheless the respirable dust generated from these bales was nearly completely inactivated and dust levels were reduced. Presumably a large quantity of respirable material was extracted from the bound bale and/or bound to the fibre, making it unavailable for later release upon processing. When condensation from the exhaust from the production steamer was collected, it was consistently dark brown in colour. When not collected, the exhaust material fell to the roof of the plant as a fine reddish-brown powder which covered several square metres of the roof top.

Heating cotton in a drying oven appeared to increase biological activity per milligramme of cotton dust. Both trials with heated cotton resulted in disproportionately greater drops in $\mathrm{FEV}_{\mathbf{1 . 0}}$ and greater numbers of workers reporting chest tightness and/or dyspnoea than did exposures to raw cotton dust at the same dust levels. Whether this increase in activity is due to chance, to a change in the physical composition of the dust (relatively greater concentration of finer particles), or to actual changes in chemical activity of the agent(s) is unknown.

Two materials under study as possible aetiological agents in byssinosis are consistent with selective steam extraction. Hitchcock, Piscitelli, and Bouhuys (1971) have described a steam volatile substance 
which has some of the properties of methyl piperonylate. Taylor, Massoud, and Lucas (1971) have described a condensed polyphenol based on leukocyanidin which is extracted by steam (Taylor, personal communication). Indeed, the material which falls from the steamer exhaust onto the mill roof top has the appearance of the material produced by Taylor. It is also of interest that a typical polyphenolic monomer, quercetin, found in the cotton plant is commercially prepared by steam distilling black oak bark.

\section{Preprocessing cotton to prevent byssinosis}

Provided this human panel was a sensitive indicator of byssinosis susceptibility, the results of these trials suggest that washing cotton could eliminate byssinosis. Unfortunately, manufacturing trials found that washed cotton did not process well. Because washing cotton appears to eliminate completely biological activity, further efforts should be made to wash cotton, perhaps with another solvent, in a manner compatible with subsequent processing. Steaming cotton, although not as effective in reducing biological activity, was found to reduce respirable dust levels and also to reduce the biological activity of the remaining respirable dust. In addition, the spinning quality of the yarn has not been significantly altered in extensive manufacturing trials. Based on these findings, a plant wide intervention trial with steamed cotton has begun in this mill which has been studied prospectively for two years.

As noted in Manchester over 10 years ago, a major advantage of pre-manufacturing cleaning of cotton over conventional dust removal would be one of cost. Although accurate cost estimates are not yet available, it is known that such a process is economically attainable by any manufacturer. A second advantage, in addition to respirable dust reduction, is an apparent reduction in biological activity of the remaining dust. This becomes important when one considers the cost and likelihood of achieving a reasonably safe exposure level of $0.1 \mathrm{mg} / \mathrm{m}^{3}$ for raw respirable dust (Merchant et al., 1973b). A third major advantage is that this process could be implemented at the cotton gin, thereby reducing exposure to ginners and all others who subsequently process cotton. In addition to the United States textile worker, workers in countries which import American cotton would benefit froni this application.

Despite these encouraging experimental results, several questions concerning the efficacy of steaming must be answered before it could be adopted. Its environmental and manufacturing effectiveness must be proven in extensive manufacturing intervention trials and dose-response curves developed for steamed cotton dust. Specific technical information about optimal steam application and control must be defined. ,The question whether steamed cotton dust could be adequately measured gravimetrically without a bioassay to detect the amount of active agent(s) must be raised. Because biological activity remains in steamed cotton dust, much improved machine exhaust ventilation, particularly in opening, picking, and carding areas, is necessary to provide a safe working environment, and medical surveillance of workers is mandatory.

The authors wish to express their thanks to the many who participated in and contributed to this study. Dr. Carl Shy, Environmental Protection Agency, provided valuable advice on the experimental design and continuing encouragement. Mrs. Karen Copeland willingly completed the tedious statistics. Mr. Don Powell provided medical illustration. The management of Burlington Industries deserves credit for their role in making this study possible by providing the exposure chamber, raw materials, and steamer development. Thanks go to the management and employees of the Smithfield Spinning Plant, and especially to the 16 members of the the panel whose spirit and good humour through one and a half years of 15408 forced expirations contributed immeasurably to the success of these trials.

\section{References}

Berry, G., and Molyneux, M. K. (1968) The correlation of cotton dust exposure and physiological response. Proceedings of the International Conference on Respiratory Disease in Textile Workers, Alicante, Spain, pp. 184-187.

Boren, H. G., Kory, R. C., and Syner, J. C. (1966). The Veterans Administration-Army cooperative study of pulmonary function. II. The lung volume and its subdivisions in normal men. American Journal of Medicine, 41, 96-114.

Bouhuys, A., Lindell, S. E., and Lundin, G. (1960). Experimental studies on byssinosis. British Medical Journal, 1, 324-326.

, Wolfson, R. L., Horner, D. W., Brain, J. D., and Zuskin, E. (1969). Byssinosis in cotton textile workers - respiratory survey of a mill with rapid labor turnover. Annals of Internal Medicine, 71, 257-269.

Carey, G. C. R., Elwood, P. C., McAulay, I. R., Merrett, J. D., and Pemberton, J. (1965). Byssinosis in Flax Workers in Northern Ireland. H.M.S.O., Belfast.

Collis, E. L. (1915-16). Industrial pneumoconioses with special reference to chest phthisis (Milroy Lectures). Public Health, 28, 252-264; 29, 11-20, 37-44.

Dixon, W. J., and Massey, F. J. (1969). Introduction to Statistical Analysis, 3rd ed., pp. 207-209. McGraw-Hill, New York.

El-Batawi, M. A., and El-Din Shash, S. (1962). An epidemiological study on aetiological factors in byssinosis. Internationales Archiv für Gewerbepathologie und Gewerbehygiene, 19, 393-402.

- , and Hussein, M. (1964). Endemic byssinosis in an Egyptian village. British Journal of Industrial Medicine, 21, 231-234.

_, Schilling, R. S. F., Valić, F., and Walford, J. (1964). Byssinosis in Egyptian cotton industry: changes in ventilatory capacity during the day. British Journal of Industrial Medicine, 21, 13-19.

Hamilton, J. D., Halprin, G. M., Kilburn, K. H., Merchant, J. A., and Ujda, J. R. (1973). Differential aerosol challenge studies in byssinosis. Archives of Environmental Health (In press). 
Hitchcock, J., Piscitelli, D. M., and Bouhuys, A. (1971). Histamine release from human lung by a component of cotton bracts (Abstract). Federation Proceedings, 55th Annual Meeting, 30, No. 2.

Lynch, J. R. (1970). Air sampling for cotton dust. Transactions of the National Conference on Cotton Dust and Health. University of North Carolina, Chapel Hill.

McDermott, 'M., Skidmore, J. W., and Edwards, J. (1968). The acute physiological, immunological and pharmacological effects of inhaled cotton dust in normal subjects. Proceedings of the International Conference on Respiratory Disease in Textile Workers, Alicante, Spain, pp. 133-147.

McKerrow, C. B., Roach, S. A., Gilson, J. C., and Schilling, R. S. F. (1961). The size of cotton dust particles causing byssinosis: an environmental and physiological study. British Journal of Industrial Medicine, 19, 1-8.

—, and Schilling, R. S. F. (1961). A pilot enquiry into byssinosis in two cotton mills in the United States. Journal of the American Medical Association, 177, 850-853.

Merchant, J. A., Kilburn, K. H., O'Fallon, W. M., Hamilton, J. D., and Lumsden, J. C. (1972). Byssinosis and chronic bronchitis among cotton textile workers. Annals of Internal Medicine, 76, 423-433.

, Lumsden, J. C., Kilburn, K. H., O'Fallon, W. M., Ujda, J. R., Germino, V. H., and Hamilton, J. D. (1973a). An industrial study of the biological effects of cotton dust and cigarette exposure. Proceedings of the 1972 Skytop Conference on Respiratory Disease in Industry. Journal of Occupational Medicine (In press).

- - - - - - - - (1973b). Dose response studies of cotton textile workers. Proceedings of the 1972 Skytop Conference on Respiratory Disease in Industry. Journal of Occupational Medicine (In press).

Molyneux, M. K., and Berry, G. (1968). The correlation of cotton dust exposure with the prevalence of respiratory symptoms. Proceedings of the International Conference on Respiratory Disease in Textile Workers, Alicante, Spain, pp. 177-183.
_ study of respiratory symptoms in Lancashire mills, 1963-66. British Journal of Industrial Medicine, 27, 225234.

Roach, S. A., and Schilling, R. S. F. (1960). A clinical and environmental study of byssinosis in the Lancashire cotton industry. British Journal of Industrial Medicine, 17, 1-9.

Schilling, R. S. F. (1956). Byssinosis in cotton and other textile workers. Lancet, 2, 261-265.

_-, Vigliani, E. C., Lammers, B., Valić, F., and Gilson, J. C. (1964). A report on a conference on byssinosis. In XIVth International Congress on Industrial Health, Madrid, 1963, Vol. 2, pp. 137-145. Excerpta Medica International Congress Series No. 62.

Schrag, P. E., and Gullet, A. D. (1970). Byssinosis in cotton textile mills. American Review of Respiratory Disease, 101, 497-503.

Sutinen, S., Christoforidis, A. J., Klugh, G. A., and Pratt, P. C. (1965). Roentgenologic criteria for the recognition of nonsymptomatic pulmonary emphysema. American Review of Respiratory Disease, 91, 69-76.

Taylor, G., Massoud, A. A. E., and Lucas, F. (1971). Studies on the aetiology of byssinosis. British Journal of Industrial Medicine, 28, 143-151.

Wood, C. H., and Roach, S. A. (1964). Dust in cardrooms: a continuing problem in the cotton-spinning industry. British Journal of Industrial Medicine, 21, 180-186.

Zuskin, E., Wolfson, R. L., Harpel, G., Welborn, J. W., and Bouhuys, A. (1969). Byssinosis in carding and spinning workers. Archives of Environmental Health, 19, 666-673.

Received for publication August 14, 1972. 
APPENDIX 1

Raw Materials and Preprocessing by Trial

\begin{tabular}{|c|c|c|}
\hline Trial & Material & Preprocessing \\
\hline 1 & None & None \\
\hline 2 & Rayon & None \\
\hline 3 & $\begin{array}{l}\text { Strict middling } \\
\text { cotton, low } \\
\text { gossypol content }\end{array}$ & None \\
\hline 4 & $\begin{array}{l}\text { Strict middling } \\
\text { cotton }\end{array}$ & None \\
\hline 5 & $\begin{array}{l}50 \% \text { strict middling } \\
\text { cotton, } 50 \% \\
\text { polyester }\end{array}$ & None \\
\hline $6 \& 7$ & $\begin{array}{l}\text { Strict low middling } \\
\text { cotton }\end{array}$ & None \\
\hline 8 & $\begin{array}{l}\text { Strict low middling } \\
\text { cotton }\end{array}$ & Processed through the picking process \\
\hline $9 \& 10$ & $\begin{array}{l}\text { Strict low middling } \\
\text { cotton }\end{array}$ & Dry heat of $107 \cdot 2^{\circ} \mathrm{C}$ for $5 \mathrm{~min}$ \\
\hline 11 & $\begin{array}{l}\text { Strict low middling } \\
\text { cotton }\end{array}$ & $\begin{array}{l}\text { Washed in large raw stock dyeing vat following steaming with wetting agent }{ }^{1} \text { and } \\
0.6 \% \mathrm{NaOH} \text { in water at } 100^{\circ} \mathrm{C} \text { for } 30 \mathrm{~min}\end{array}$ \\
\hline 12 & $\begin{array}{l}\text { Strict low middling } \\
\text { cotton }\end{array}$ & $\begin{array}{l}\text { Washed in a large raw stock dyeing vat following steaming with wetting agent }{ }^{1} \text { in } \\
\text { water at } 100^{\circ} \mathrm{C} \text { for } 30 \text { min }\end{array}$ \\
\hline 13 & $\begin{array}{l}\text { Strict low middling } \\
\text { cotton (different } \\
\text { source) }\end{array}$ & $\begin{array}{l}\text { Commercially prepared for medical use by boiling at } 132.2{ }^{\circ} \mathrm{C} \text { with } 0.6 \% \text { caustic solution, } \\
\text { washed with soap and tetrasodium pyrophosphate, bleached with a } 0.1 \% \text { solution } \\
\text { of sodium hypochlorite and scoured with sulphuric acid at a pH of less than } 2 \text {, } \\
\text { then washed to a pH of } 6.0 \text { to } 7.0\end{array}$ \\
\hline $14 \& 15$ & $\begin{array}{l}\text { Strict low middling } \\
\text { cotton }\end{array}$ & Steamed in large dyeing vat under no pressure for $30 \mathrm{~min}$ at $100^{\circ} \mathrm{C}$ \\
\hline 16 & $\begin{array}{l}\text { Strict low middling } \\
\text { cotton }\end{array}$ & $\begin{array}{l}\text { Cotton introduced through a feeder onto a conveyor, sprayed with a } 1 \% \text { aqueous } \\
\text { solution of wetting agent with } 100 \% \text { pick-up and dried at } 162 \cdot 8{ }^{\circ} \mathrm{C}\end{array}$ \\
\hline 17 & $\begin{array}{l}\text { Strict low middling } \\
\text { cotton }\end{array}$ & $\begin{array}{l}\text { Cotton introduced through a feeder onto a conveyor, sprayed with a } 1 \% \text { solution of } \\
\text { wetting agent with } 50 \% \text { pick-up, passed under perforated steam paper with } \\
207 \mathrm{kN} / \mathrm{m}^{2} \text { of steam and oven-dried at } 162 \cdot 8^{\circ} \mathrm{C}\end{array}$ \\
\hline $18 \& 19$ & $\begin{array}{l}\text { Strict low middling } \\
\text { cotton }\end{array}$ & $\begin{array}{l}\text { Bound, burlap covered, unopened bales placed in a large autoclave, steamed for } 5 \\
\text { min with } 207, \mathrm{kN} / \mathrm{m}^{2} \text { of steam, evacuated to } 610 \mathrm{~mm} \mathrm{Hg} \text {, steamed and evacuated } \\
\text { as before, then steamed again for } 45 \mathrm{~min} \text { and then evacuated }\end{array}$ \\
\hline 20 & $\begin{array}{l}\text { Strict low middling } \\
\text { cotton }\end{array}$ & $\begin{array}{l}\text { Cotton hand fed into a small pipe steamer, steamed at } 105^{\circ} \mathrm{C} \text { for } 5 \mathrm{~min} \text {, then sprayed } \\
\text { with } 1 / 4 \% \text { solution of wetting agent and oven-dried at } 162.8 \mathrm{C}^{\circ}\end{array}$ \\
\hline 21 & $\begin{array}{l}\text { Strict low middling } \\
\text { cotton }\end{array}$ & Cotton hand fed into a small pipe steamer, steamed at $105^{\circ} \mathrm{C}$ for $5 \mathrm{~min}$ \\
\hline $22,23,24$ & $\begin{array}{l}\text { Strict low middling } \\
\text { cotton }\end{array}$ & Pipe steamer modified to allow automatic feeding, steamed at $105^{\circ} \mathrm{C}$ for $5 \mathrm{~min}$ \\
\hline $25,26,27$ & $\begin{array}{l}\text { Strict low middling } \\
\text { cotton }\end{array}$ & $\begin{array}{l}\text { Cotton steamed in a production model pipe steamer installed in the mill with a } \\
\text { steaming duration of } 7 \text { min }\end{array}$ \\
\hline $\begin{array}{l}28,29,30 \\
31,33 \\
32\end{array}$ & $\begin{array}{l}\text { Strict low middling } \\
\text { cotton } \\
50 \% \text { strict low } \\
\text { middling cotton, } \\
50 \% \text { rayon }\end{array}$ & $\begin{array}{l}\text { Cotton steamed in production model steamer with a steaming duration of } 5 \mathrm{~min} \\
\text { Cotton steamed in production model steamer with a steaming duration of } 5 \mathrm{~min}\end{array}$ \\
\hline
\end{tabular}

${ }^{1}$ Wetting agent $=$ BI Penetrant SDP, a biodegradable detergent dodecyl benzene sulphonate with an excess of sodium hydroxide to give a pH of 12 and $1 \%$ isopropyl alcohol to accelerate wetting 
APPENDIX 2

Summary of Exposure Trials

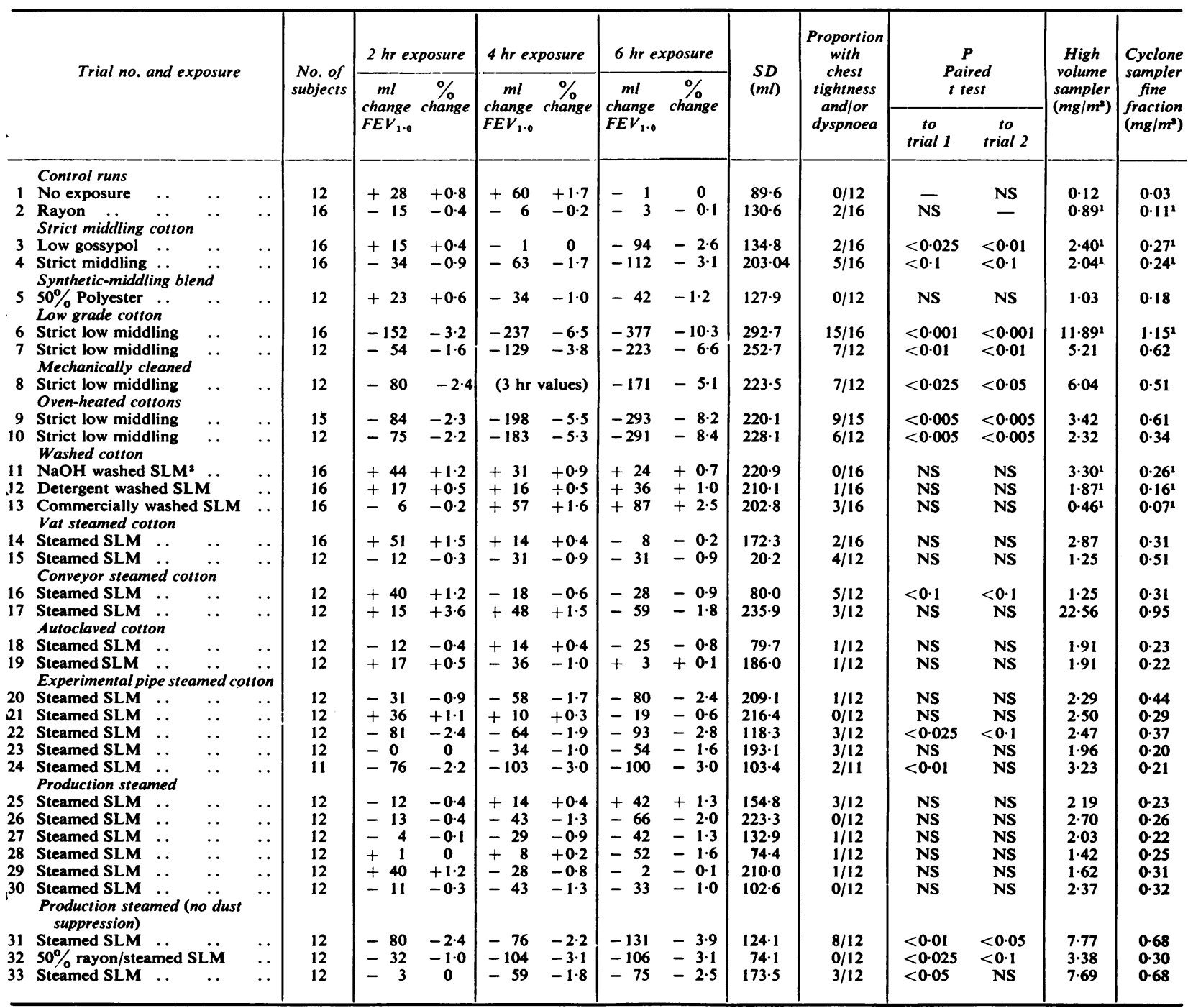

